\title{
Применение сорбентов различной природы для извлечения нестероидных противовоспалительных препаратов из водных сред (обзор)
}

\author{
(C2021 Кушнир А.А. ${ }^{1}$, Сыпко К.С. ${ }^{2}$, Губин А.С. ${ }^{1}$, \\ Шеремет Е.O. ${ }^{1}$, Суханов П.Т. ${ }^{1}$ \\ ${ }^{1}$ Воронежский государственный университет инженерных технологий, Воронеж \\ ${ }^{2}$ Невинномысский технологический институт (филиал) \\ Северо-Кавказский федеральный университет, Невинномысск \\ Поступила в редакцию 24.01.2021 г.
}

DOI: $10.17308 /$ sorpchrom.2021.21/3354

Нестероидные противовоспалительные препараты (НПВС) относятся к группе противовоспалительных, обезболивающих, жаропонижающих средств и являются одними из самых потребляемых населением фармацевтических препаратов во всем мире. НПВС характеризуются побочными эффектами и в окружающей среде биодеградируют с образованием не менее токсичных соединений. Определение нестероидных противовоспалительных препаратов на уровне микроконцентраций даже с применением чувствительных методов анализа возможно только после предварительного концентрирования. Цель работы - на основании международных баз данных обобщить применение сорбентов различной природы (в том числе природного происхождения) для сорбции нестероидных противовоспалительных препаратов.

Для концентрирования широкое применение нашли активные угли, биоугли, материалы на основе графена, карбоксилированных и некарбоксилированных многослойных углеродных нанотрубок и другие материалы на основе углерода (графеноподобный нитрид углерода, оксид графена, хитозан, нитрид углерода). Наноструктурированные кремниевые, глиняные материалы (ГМ), а также наногетероструктуры на основе ГМ экономически эффективны, характеризуются мезопористой структурой и высокой площадью поверхности. Для их модифицирования применяют катионные поверхностно-активные вещества (ПАВ) и ионные жидкости. Для получения более развитой поверхности и увеличения количества функциональных групп предложено активировать сорбенты физическими (термическая активация в токе газов) или химическими (применение неорганических кислот, солей и щелочей) методами. Методами преципитации и двойного импринтинга синтезированы молекулярноимпритированные полимеры, а суспензионно-эмульсионной полимеризацией - сшитые полимеры и гибридные полимерные материалы. Популярными сорбентами для извлечения НПВС являются магнитные наносорбенты и металлорганические полимеры.

В обзоре приведены условия сорбции (рН, объем раствора, время достижения сорбционного равновесия, масса сорбента), представлены хемометрические алгоритмы оптимизации условий сорбции и величины предельной сорбции диклофенака, ибупрофена, ацетилсалициловой кислоты материалами различной природы. Изложены возможные механизмы сорбции, кинетические и сорбционные модели.

Ключевые слова: нестероидные противовоспалительные препараты, сорбция, активные угли, биоугли, природные сорбенты, углеродные материалы, полимерные сорбенты.

\section{Введение}

Фармацевтические препараты - обширный класс химических веществ, включающий антибиотики, стероиды, противовоспалительные лекарства, седативные средства, противоэпилептические препараты, обезболивающие, гипотензивные лекарства, снотворные, препараты для похудения и другие [1]. 
Наличие фармпрепаратов и их метаболитов в грунтовых и поверхностных водах весьма опасно и не всегда предсказуемо для окружающей среды [2]. Большинство из них поступают в окружающую среду вследствие неправильной и неполной очистки сточных вод на очистных сооружениях. Часто в реках, озерах и сточных водах очистных сооружений присутствуют диклофенак (ДК), ибупрофен (ИБ) и некоторые другие нестероидные противовоспалительные препараты (НПВС). Они относятся к группе противовоспалительных, обезболивающих, жаропонижающих средств [3] и являются одними из наиболее потребляемых населением фармацевтических препаратов во всем мире [4].

НПВС характеризуются побочными эффектами $[5,6]$. После потребления человеком или животными они неполностью метаболизируются и выводятся из организма. Ферменты, присутствующие в организме человека и животных, метаболизируют НПВС в более токсичные, чем исходные соединения вещества. (например, ИБ - в карбоксиибупрофен, гидроксиибупрофен и карбоксигидратроповую кислоту) [7]. В окружающей среде НПВС биодеградируют с образованием 4-изобутирикбензальдегида, 1-(4изобутилфенил)-1-этанола, 2-[4-(1-гидроксиизобутил) фенилпропионовой кислоты, 4-этилфенола, 4-этилбензальдегида, 1-этил4-(1-гидрокси) изобутилбензола [12-15].

Даже в следовых количествах НПВС при длительном воздействии вызывают у человека эндокринные нарушения, индукцию антиоксидантного стресса, нарушения развития скелета и иммунной функции, при попадании в водные среды оказывают негативное влияние на гидробиоту [8-11]. Формальным доказательством опасного действия даже незначительных количеств лекарств на окружающую среду являются значения показателя опасности - аналога ПДК, введенного Агентством по охране окружающей среды США (US EPA) [16]. Исходя из доклада Всемирной организации здраво- охранения «Pharmaceuticals in drinking water», содержание НПВС не должно превышать в воде 0.25-0.50 нг/дм ${ }^{3}$ [17]. Европейский Союз включил ДК в список приоритетных органических веществ (2013/39/EU) и установил приемлемую концентрацию до 100 нг/дм ${ }^{3}$ для внутренних водоемов и 10 нг/дм ${ }^{3}$ для прибрежных вод $[18,19]$.

Цель работы - на основании международных баз данных обобщить результаты применения сорбентов различной природы (в том числе природного происхождения) для сорбции нестероидных противовоспалительных препаратов.

\section{Сорбция активными углями, биоуглями и материалами на их основе}

Активный уголь (АУ) уже много десятилетий является распространенным сорбентом для извлечения из вод загрязнителей различного происхождения, в том числе органических. Сорбционная активность АУ обусловлена развитой пористой структурой (большие объемы пор) и различными химическими свойствами поверхности, обусловленными наличием или отсутствием гетероатомов на краях графитовой плоскости [21].

Изучена адсорбция ИБ коммерческим гранулированным АУ (Filtrasorb 400, Calgon Carbon Corporation), полученным из битуминозного угля [21]. В качестве альтернативного и недорогого (себестоимость в сравнении с полимерными сорбентами значительно ниже) адсорбента для сорбции ацетилсалициловой кислоты (АК) применяют АУ, полученный из коммерческого угля (кокосового субстарата) марки Tobasa Agroindustrial (Tocantins, Бразилия) [22], а для сорбции ДК - АУ марок «Êxodo Científica» [23] и «Aldrich» [24] (табл. 1).

Предложены возможные механизмы сорбции АК сорбентом на основе кокосового субстрата [22]. Сорбция АК зависит от заряда поверхности АУ (при $\mathrm{pH}$ $2.0,3.5$ и 6.4 поверхность заряжена положительно, при $\mathrm{pH} 10.0$ - отрицательно) 
Таблица 1. Сорбция ацетилсалициловой кислоты (АК), ибупрофена (ИБ), диклофенака (ДК) сорбентами на основе активного угля, биоуглей и материалов на их основе, условия их активации, модификации

Table 1. Sorption of acetylsalicylic acid (AA), ibuprofen (IB), diclofenac (DC) by sorbents based on activated carbon, biochar and materials based on them, and conditions for their activation and modification

\begin{tabular}{|c|c|c|c|c|c|c|c|c|c|}
\hline \multirow[b]{2}{*}{ Марка (основа) } & \multirow{2}{*}{$\begin{array}{c}\text { Способ акти- } \\
\text { вации/ моди- } \\
\text { фикация }\end{array}$} & \multirow[b]{2}{*}{$\begin{array}{l}\text { Cop- } \\
\text { бат }\end{array}$} & \multicolumn{4}{|c|}{ Условия сорбции } & \multirow[b]{2}{*}{$\begin{array}{c}t, \\
\text { мин }\end{array}$} & \multirow[b]{2}{*}{$\begin{array}{c}a_{\mathrm{p}}, \\
\mathrm{M} \Gamma / \Gamma\end{array}$} & \multirow[b]{2}{*}{$\begin{array}{l}\text { Лите- } \\
\text { ратура }\end{array}$} \\
\hline & & & $\begin{array}{c}C o, \\
\mathrm{M} / \mathrm{dM}^{3} \\
\end{array}$ & $\mathrm{pH}$ & $\begin{array}{c}m, \\
\Gamma\end{array}$ & $\begin{array}{c}V, \\
\mathrm{Cm}^{3}\end{array}$ & & & \\
\hline 1 & 2 & 3 & 4 & 5 & 6 & 7 & 8 & 9 & 10 \\
\hline Filtrasorb 400 & БА & ИБ & 10 & 6.8 & 0.01 & 50 & н.д. & 38.32 & [21] \\
\hline $\begin{array}{c}\text { КУ кокосовый } \\
\text { субстарат }\end{array}$ & БА & AK & 50 & 2 & 0.1 & 10 & 200 & 19.8 & [22] \\
\hline $\begin{array}{l}\text { KY Êxodo } \\
\text { Científica }\end{array}$ & БА & ДК & $\begin{array}{c}10- \\
1500\end{array}$ & 5.5 & 1 & 100 & 1440 & 46.22 & [23] \\
\hline $\begin{array}{l}\text { KУ Aldrich (1), } \\
\text { Prolabo (2) }\end{array}$ & БА & ДК & 50 & 10.1 & н.д. & н.д. & 120 & $\begin{array}{c}0.00021 \\
0.00037 \\
\text { моль/г }\end{array}$ & [24] \\
\hline $\begin{array}{l}\text { Laminaria } \\
\text { japonica }\end{array}$ & $\begin{array}{c}\mathrm{TA}\left(400^{\circ} \mathrm{C}, \text { газ }\right. \\
\left.-\mathrm{N}_{2}\right) \text { и } \mathrm{FeCl}_{3}\end{array}$ & AK & 100 & 3.41 & 0.05 & 40 & 420 & 127 & [26] \\
\hline $\begin{array}{c}\text { КУ на основе } \\
\text { кокосовой } \\
\text { шелухи }\end{array}$ & БА (1); УЗ (2) & ИБ & 100 & 2 & $\begin{array}{r}m / \\
0.5 \mathrm{r}\end{array}$ & & 120 & $\begin{array}{c}85(1) \\
107.1 \\
(2) \\
\end{array}$ & [27] \\
\hline $\begin{array}{c}\text { Резеркинол / } \\
\text { формальдегид }\end{array}$ & $\begin{array}{c}\text { TA }(973 \text { К, газ } \\
\left.-\mathrm{N}_{2}\right)\end{array}$ & ИБ & $10-35$ & 2 & 0.05 & 50 & 20 & $\begin{array}{c}6.472 \\
\pi / \mathrm{M \Gamma}\end{array}$ & [28] \\
\hline Листья пальмы & $\begin{array}{c}\mathrm{XA}: \mathrm{KOH}, \\
\text { HNO } \\
\text { ЭД, ЭА }\end{array}$ & ИБ & 100 & 7 & 0.06 & 25 & $\begin{array}{c}1440 \\
(1) \\
600\end{array}$ & $\begin{array}{l}41.66 \\
53.76 \\
18.98 \\
25.32\end{array}$ & [30] \\
\hline $\begin{array}{c}\text { Уголь } \\
\text { Sigma-Aldrich } \\
\end{array}$ & $35 \% \mathrm{H}_{2} \mathrm{O}_{2}$ & ИБ & $5-100$ & 3 & 0.01 & 30 & 7200 & 35.55 & [31] \\
\hline $\begin{array}{c}\text { Дуб } \\
\text { (Quercus Brantii) }\end{array}$ & $\begin{array}{c}\text { КАи ХА - } \\
\mathrm{NaOH}, \mathrm{KOH}, \\
\mathrm{NH}_{4} \mathrm{Cl}, \mathrm{ZnCl}_{2}, \\
\mathrm{H}_{3} \mathrm{PO}_{4} \\
\end{array}$ & ИБ & 100 & 3 & 0.1 & 100 & 120 & 96.15 & [32] \\
\hline Косточки оливок & $\begin{array}{c}\mathrm{KA} \mathrm{(1),XA} \mathrm{-} \\
\mathrm{H}_{3} \mathrm{PO}_{4}(2), \\
\text { мокрый способ } \\
\text { (3) }\end{array}$ & ИБ & 100 & 3 & 0.03 & 100 & 480 & $\begin{array}{l}1.37 \mathrm{MM} \\
(1) \\
0.78 \mathrm{MM} \\
20.70 \\
\mathrm{MM}\end{array}$ & [33] \\
\hline $\begin{array}{c}\text { Стручки Моринги } \\
\text { масличной } \\
\end{array}$ & $\mathrm{XA}-\mathrm{HCl}$ & ДК & 50 & 7 & 0.1 & 50 & 480 & 60.8 & [34] \\
\hline $\begin{array}{c}\text { Клубни } \\
\text { Цикламена } \\
\text { персидского }\end{array}$ & $\begin{array}{c}\mathrm{TA}(550 \mathrm{~K}, \\
\left.\text { газ }-\mathrm{N}_{2}\right), \mathrm{XA}_{-} \\
\mathrm{KOH}, \mathrm{H}_{3} \mathrm{PO}_{4}\end{array}$ & ДК & 50 & 4 & 0.25 & 50 & 150 & 22.22 & [35] \\
\hline Скорлупа какао & БА & ДК & 100 & 4 & 0.05 & 2.5 & 120 & 63.47 & [36] \\
\hline $\begin{array}{c}\text { АУ из сахарного } \\
\text { тростника }\end{array}$ & $\mathrm{ZnCl}_{2}$ & ДК & $\begin{array}{c}50 \\
\mathrm{ppm}\end{array}$ & 2 & $\begin{array}{r}m / V \\
\Gamma / \text { д }\end{array}$ & $\begin{array}{l}0.4 \\
1^{3} \\
\end{array}$ & 15 & 315 & [37] \\
\hline Целлюлоза & $\begin{array}{l}\text { TA }(800 \mathrm{~K}, \\
\left.\text { газ }-\mathrm{N}_{2}\right)\end{array}$ & $\begin{array}{l}\text { ДК } \\
\text { ИБ }\end{array}$ & 100 & 7.6 & & 0.4 & 200 & $\begin{array}{l}23.38 \\
12.93 \\
\end{array}$ & {$[38]$} \\
\hline $\begin{array}{l}\text { КУС0, Kuraray } \\
\text { Chemical Co. }\end{array}$ & БА & ИБ & $5-180$ & 3 & 0.01 & 100 & 600 & 491.9 & [41] \\
\hline $\begin{array}{c}\text { Производство } \\
\text { Dacarb } \\
\end{array}$ & БА & ДК & 10 & 7.5 & 20 & 1 л & 3000 & 1525.8 & [43] \\
\hline Аэрогель & Пиролиз & ИБ & 10 & 4 & 0.02 & 50 & 20 & 7.43 & [44] \\
\hline Сосновая щепа & $\begin{array}{c}\text { TA }(698 \mathrm{~K}, \\
\left.\text { га3 }-\mathrm{N}_{2}\right)\end{array}$ & ИБ & $25-100$ & 3 & & 4 & 960 & 10.74 & [45] \\
\hline
\end{tabular}




\begin{tabular}{|c|c|c|c|c|c|c|c|c|c|}
\hline 1 & 2 & 3 & 4 & 5 & 6 & 7 & 8 & 9 & 10 \\
\hline $\begin{array}{c}\text { Водоросли } \\
\text { Bifurcaria } \\
\text { bifurcata }\end{array}$ & $\begin{array}{c}\mathrm{TA}\left(600^{\circ} \mathrm{C}, \text { газ }\right. \\
\left.-\mathrm{N}_{2}\right)\end{array}$ & $\mathrm{AK}$ & 150 & 3.41 & 0.02 & 100 & 120 & 2633 & {$[46]$} \\
\hline Наноматериал & $\begin{array}{l}\mathrm{Fe} / \mathrm{N}-ц и к л о- \\
\text { декстрин }\end{array}$ & $\mathrm{AK}$ & 150 & 2.5 & 0.05 & 50 & 30 & 101 & [47] \\
\hline $\mathrm{AY}$ & $\mathrm{H}_{3} \mathrm{PO}_{4} / 600^{\circ} \mathrm{C}$ & $\mathrm{AK}$ & 100 & 3 & 0.5 & 50 & 60 & 178.57 & {$[48]$} \\
\hline $\mathrm{AY}$ & $\mathrm{XA} \mathrm{H}_{3} \mathrm{PO}_{4}$ & $\mathrm{AK}$ & 60 & 2.1 & 2 & 50 & 90 & 178.89 & [49] \\
\hline $\begin{array}{l}\text { Растение P. } \\
\text { Hysterophorus }\end{array}$ & $\begin{array}{c}\mathrm{XA}-2 \mathrm{M} \\
\mathrm{NaOH}\end{array}$ & ИБ & 20 & 4 & 0.05 & 100 & 120 & 90.46 & {$[50]$} \\
\hline $\begin{array}{l}\text { Сахарный } \\
\text { тростник }\end{array}$ & $\begin{array}{c}\text { TA: газ }-\mathrm{N}_{2}(1) \\
\mathrm{XA}-\mathrm{H}_{3} \mathrm{PO}_{4} \\
(2)\end{array}$ & ИБ & 10 & 3 & н.д. & 1.66 & 180 & $\begin{array}{l}11.90(1) \\
13.51(2)\end{array}$ & {$[51]$} \\
\hline Кедровая щепа & $\begin{array}{l}\text { TA: чистый } \mathrm{N}_{2} \\
(1), \text { смесь } \mathrm{N}_{2} \text { и } \\
\mathrm{O}_{2}(2)\end{array}$ & $\begin{array}{l}\text { ДК** } \\
\text { ИБ }\end{array}$ & $\begin{array}{c}20 \\
\mathrm{MM}\end{array}$ & 3 & н.д. & 2 & 10080 & $\begin{array}{c}(1) 372^{*}, \\
311^{* *} ; \\
(2) \\
214^{*} \\
286^{* *}\end{array}$ & {$[52]$} \\
\hline $\begin{array}{c}\text { KY Hydrodalco } \\
3000 \\
\end{array}$ & БА & $\begin{array}{l}\text { ИБ* } \\
\text { ДК** }\end{array}$ & 15 & 6 & 50 & 10 & 120 & $\begin{array}{c}64^{*} \\
34^{* *}\end{array}$ & {$[54]$} \\
\hline KУ F400 & БА & ДК & н.д. & 7 & н.Д. & 10 & 4320 & 194.9 & {$[55]$} \\
\hline Косточки оливок & $\begin{array}{c}\text { TA }(500 \mathrm{~K}, \text { газ } \\
\left.-\mathrm{N}_{2}\right)\end{array}$ & ДК & 20 & 2 & 0.25 & 50 & 30 & 11,0 & {$[56]$} \\
\hline КУ & $\mathrm{XA}: \mathrm{H}_{2} \mathrm{SO}_{4}$ & ДК & $\begin{array}{l}25- \\
100\end{array}$ & 2 & 5 & 25 & 1440 & 487 & {$[57]$} \\
\hline $\begin{array}{c}\text { Паста на основе } \\
\text { лигнина }\end{array}$ & TA $\left(\right.$ газ $\left.-\mathrm{N}_{2}\right)$ & ДК & $\begin{array}{l}10- \\
300\end{array}$ & 2 & 0.03 & 20 & 480 & 71.77 & {$[58]$} \\
\hline $\begin{array}{c}\text { Сахарный } \\
\text { тростник }\end{array}$ & $\begin{array}{c}\text { TA }(500 \mathrm{~K}, \text { газ } \\
\left.-\mathrm{N}_{2}\right), \mathrm{XA}^{-} \\
\mathrm{ZnCl}_{2}\end{array}$ & ДК & 50 & 2 & н.д. & 0.4 & 15 & 315.0 & [59] \\
\hline
\end{tabular}

БА - без активации, ТА - термоактивация, ХА - химическая активация, УЗ - ультразвук, КУ - коммерческий уголь, ЭД - этилендиамин, ЭА - этиламин, КА - карбонизация.

WA - without activation, TA - thermal activation, CA - chemical activation, US - ultrasound, CC - commercial coal, ED - ethylenediamine, EA - ethylamine, CA - carbonization.

и степени ионизации АК в растворе. Таким образом, сорбция сорбата может уменьшаться из-за отталкивания одинаковых зарядов АК и поверхности АУ. Значение $\mathrm{pK}_{\mathrm{a}}$ АК в водном растворе составляет 3.5, при $\mathrm{pH} 2.0-3.5$ она присутствует в растворе в виде нейтральных молекул, при $\mathrm{pH}$ 6.4-10.0 - в виде анионов. В связи с этим предположены следующие возможные механизмы сорбции АК:

- в следствие электростатического взаимодействия (вытекающее из закона Кулона) между ионами АК и заряженной поверхностью адсорбента;

- за счет образования водородных связей между адсорбентом и карбоксильными, лактоновыми и фенольными поверхностными группами АУ;

- в результате гидрофобных взаимодействий между функциональными группами АК и сорбатом (силы Ван-дерВаальса).

Схема механизмов сорбции приведена на рис. 1 и аналогична сорбции ИБ активным углем, полученным на основе сахарного тростника [37].

Для получения более развитой поверхности и увеличения количества функциональных групп предложено активировать АУ физическими (термическая активация в токе газов) или химическими (применение неорганических кислот, солей и щелочей) методами. Физическая активация позволяет удалить смолистые продукты, выделяющиеся во время предварительного сжигания образцов и заполняющие поры углей [25]. Способы активации, условия сорбции, а также ее предельные значения приведены в табл. 1. 


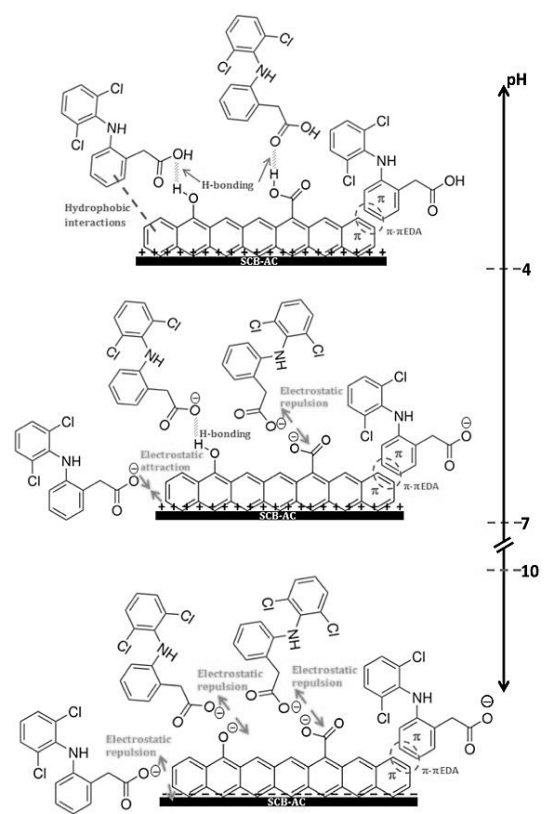

Рис. 1. Схема механизмов сорбции ибупрофена активным углем на основе сахарного тростника [37].

Fig. 1. Scheme of the mechanisms of ibuprofen sorption by activated carbon based on sugar cane [37].

Пиролизом в атмосфере азота в кварцевом трубчатом реакторе при $400^{\circ} \mathrm{C}$ в течение 1 ч из водоросли Laminaria japonica (L. japonica) получен АУ, который модифицирован $\mathrm{FeCl}_{3} \cdot 6 \mathrm{H}_{2} \mathrm{O}$ [26]. Синтезированный композит (AC/Fe-MC) активировали 60-180 мин в токе азота при $600-800^{\circ} \mathrm{C}$. При оптимальных условиях активации (коэффициент пропитки - 2.62, температура активации $-727^{\circ} \mathrm{C}$, время активации составляет 129 мин) максимальная сорбционная емкость $\mathrm{AC} / \mathrm{Fe}-\mathrm{MC}$ по отношению к АК около $127 \mathrm{мг} / \Gamma$ при $10^{\circ} \mathrm{C}$. Процесс сорбции экзотермичен и регулируется в основном многоступенчатыми механизмами диффузии из-за неоднородной поверхности адсорбента.

Показана эффективность применения активации поверхности коммерческого АУ на основе кокосовой шелухи марки Peixe Bello (Бразилия) ультразвуком (мощность $400 \mathrm{BT}$, частота 24 кГц, время активации 1 ч) [27, 28]. При обработке ультразвуком изменяются структурные характеристики сорбента. Его полости взрываются и из них с высокой скоростью выходят жидкие струи, которые фрагментируют частицы сорбента, это ведет к увеличению площади поверхности сорбента (с 641 до $732 \mathrm{~m}^{2} / \Gamma$ ), объема и диаметра пор, соответственно увеличивая их на 33 и 7\%. Как следствие, сорбционная емкость материала [28] к ИБ примерно на 25\% больше по сравнению с неактивированным образцом.

Пиролизом в атмосфере азота в течение 2 ч при $500^{\circ} \mathrm{C}$ из листьев пальмы (Phoenix Dactylifera L.) получен АУ, который активировали гидроксидом калия (образец 1) [29]. В дальнейшем его окисляли $\mathrm{HNO}_{3}$ (образец 2, ОАУ). Второй образец после модифицировали этилендиамином (образец 3, BAC-EDA) и этиламином (образец 4, НАС-ЕА) для получения, соответственно, основной и гидрофобной углеродистой поверхности. Время достижения равновесия устанавливалось быстрее (10 ч) на образцах 2-4 (НAC-EA, ОАУ и ВАC-EDA), чем на АУ $(24$ ч) [30]. Предельная сорбция ИБ уменьшалась в ряду ОАУ $>$ AУ $>$ НАCEA $>$ BAC-EDA [30]. АУ характеризуется большой площадью поверхности $\left(823 \mathrm{~m}^{2} / \Gamma\right)$, причем доминирующими силами сорбции являются силы Ван-дерВаальса. НАС-ЕА, обладающий гидрофобными активными центрами (этиль- 
ные цепи), сорбирует в основном через гидрофобные взаимодействия. ОАУ продемонстрировал более высокий уровень сорбции ИБ за счет электростатических взаимодействий по аналогии с [22]. BAC-EDA характеризуется самой низкой сорбционной активностью (соседние аминогруппы этиламина на поверхности BAC-EDA затрудняют доступ молекул сорбата к первичным сорбционным центрам).

Кроме $\mathrm{KOH}$ и $35 \% \mathrm{H}_{2} \mathrm{O}_{2}$ [31] для химической активации АУ, предложено [32] применять растворы $\mathrm{NaOH}, \mathrm{NH}_{4} \mathrm{Cl}$ и $\mathrm{H}_{3} \mathrm{PO}_{4}$ в качестве активаторов, что позволяет достичь большей предельной сорбции ИБ, по сравнению с образцом 1 (2.3 раза) [29], и снизить время достижения равновесия с 1 [30] и 5 суток [31] до 120 мин [32]. Предложено модифицировать АУ, полученный из косточек оливок пиролизом в токе $\mathrm{CO}_{2}$, в присутствии фосфорной кислоты в насыщенном растворе персульфата аммония в 4 моль/дм ${ }^{3}$ серной кислоты. Изучена сорбция ИБ в статических и динамических условиях (применяли колонку диаметром 1 см, длиной 5 см). Предельная сорбция максимальна (1.37 ммоль/дм $\left.{ }^{3}\right)$ для образца АУ, активированного фосфорной кислотой [33]. Помимо косточек оливок для получения АУ применяют стручки моринги [34], клубни цикламена [35], какао [36], сахарного тростника [37] и целлюлозу [38]. Предельная сорбция ДК варьируется от 22.22 до 63.47 мг/Г (табл. 1).

На примере ИБ изучена эффективность сорбции при применении ткани с нанесенным на нее $\mathrm{AV}\left(\mathrm{C}_{0}\right.$, Kuraray Chemical Co. Ltd., Япония) [39,40]. В paботе [41] ткань окисляли раствором гипохлорита натрия или выдерживали 1 ч при $700{ }^{\circ} \mathrm{C}$ в атмосфере азота. Обработка $\mathrm{NaOCl}$ увеличивает количество фенольных и карбоновых групп, но при этом уменьшается удельная площадь поверхности и объем микропор сорбента. Термообработка приводит к незначительному увеличению удельной поверхности.
Предельная сорбция максимальна для образца АУ, полученного на основе ткани, и составляет 492 мг/г, при этом сорбционное равновесие достигается не менее чем через 600 мин. Для уменьшения времени равновесия сорбцию интенсифицируют с применением орбитального шейкера с аналоговым управлением для перемешивания раствора (250 об/мин) и облучением образца ткани ультразвуком. Время достижения равновесия уменьшается до 120 мин [42]. При применении ткани производства Dacarb [43] предельная сорбция повышается более чем на порядок, по сравнению с другими сорбентами (табл.1).

Золь-гелевой поликонденсацией получен углеродный аэрогель [44] с большой удельной площадью поверхности $\left(790 \mathrm{M}^{2} / \Gamma\right)$. Время достижения сорбционного равновесия ИБ при его начальной концентрации в растворе $10 \mathrm{мг} /$ дм $^{3}$ и $\mathrm{pH}$ 4 составляет менее 20 мин, степень извлечения - более $88 \%$. Из-за малого размера молекул ИБ, по сравнению с размером пор углеродного аэрогеля (средний диаметр пор 7.48 нм), для сорбции важны только $\pi$ - $\pi$ стэкинг-взаимодействия и образование водородных связей.

Биоуголь (БУ) получен быстрым пиролизом водоросли Bifurcaria bifurcata в реакторе (2 ч в атмосфере азота при $600^{\circ} \mathrm{C}$ ). Водоросли предварительно обрабатывают $80 \%$ серной кислотой (соотношение 1:3) и выдерживают 6 ч в ультразвуковой ванне. Полученный материал имеет микромезопористую структуру с площадью поверхности $898.2 \mathrm{~m}^{2} / \Gamma$, большим числом эфирных и сульфатных групп. По своей структуре он аналогичен полисахаридам, аминокислотам, сложным эфирам и пектину. В оптимизированных условиях степень извлечения АК более 98\% [46]. Большое количество различных функциональных групп приводит к тому, что предельная сорбция примерно в 36 раз выше по сравнению с наноуглеродными материалами [47] и в 15 раз - АУ $[48,49]$. Изучена возможность повторного использова- 
ния (10 циклов, степень десорбции более 95\%) БУ для сорбции АК после цикла сорбция-десорбция этиловым спиртом. Аналогичный подход применен в работе [50]. При выборе параметров сорбции ИБ модифицированным N-биоуглем варьировалась масса адсорбента (0.05-3 г), скорость перемешивания (80-240 об/мин), время контакта (15-240 мин), $\mathrm{pH}(2-10)$ и начальная концентрация ИБ. Максимальная степень извлечения ИБ более $99 \%$ при содержании сорбента 20 г/дм ${ }^{3}$, скорости перемешивания 160 об/мин, $\mathrm{pH} 4$, начальной концентрации сорбата $20 \mathrm{мг} /$ дм $^{3}$, времени достижения равновесия 120 мин и $20^{\circ} \mathrm{C}$.

Для получения БУ используют отходы сахарного тростника (Sugarcane Bagase) [51], растения P. Hysterophorus [50], кедровую щепу [52]. Далее угли физически термоактивируют в среде чистого азота [51] или в смеси азота и кислорода [52], а также химически активируют растворами фосфорной кислоты [51], гидроксида натрия [50]. Полученные БУ применяют для сорбции ИБ и ДК (табл. 1).

Для выяснения механизма сорбции в работе [27] построена трехмерная модель массообмена (модель объема пор и поверхностной диффузии, PVSDM 3D), показанная на рис. 2. Коэффициент поверхностной диффузии активированного образца в 1.7 раза больше, чем для известных углей. Величина общего внут- рипартикулярного потока является функцией времени и внутреннего состояния частицы. Установлено, что молекула ИБ диффундирует исключительно за счет поверхностной диффузии (диффузией в объеме пор пренебрегают).

С целью установления оптимальных условий (влияние $\mathrm{pH}$, массы адсорбента и концентрации сорбата) в работах [44, 46] применено математическое моделирование - центральный композитный дизайн (Central composite design, CCD) в сочетании с методологией поверхности отклика (RSM) [53]. Кроме CCD для выбора оптимальных условий и установления механизма сорбции Sellaoui и др. [31] предложены следующее: модель Хилла с одним и двумя энергетическими центрами сорбции, двухслойная модель с одним и двумя энергетическими центрами сорбции и их совместная модель. Исходя из них, молекулы ИБ при сорбции АУ могут быть в форме мономера $(n=1)$ или агрегатов $(n=2,3$ или 4$)$ в виде раствора адсорбата до и во время адсорбции на поверхности рецепторного участка АУ. Также [43] в работе для описания механизма сорбции ИБ тканью из активированного угля предложена модель экранировки проводникового типа для растворителей (conductor-like screening model for real solvents, COSMO-RS), которая позволила установить физический механизм сорбции (взаимодействие молекул сорбата с сор-

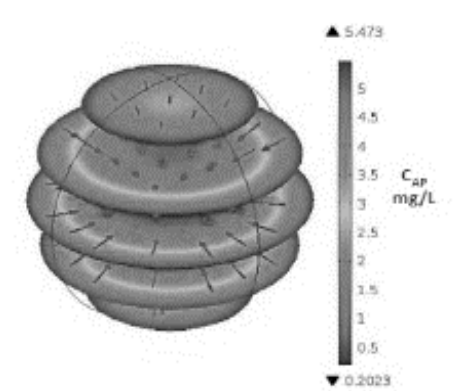

a)

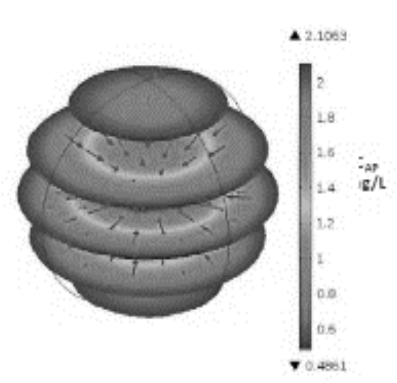

б)

Рис. 2. Модель объема пор и поверхностной диффузии (PVSDM 3D) активированного (a) и неактивированного образцов (б) [27].

Fig. 2. Pore volume and surface diffusion model (PVSDM 3D) of activated (a) and nonactivated samples (b) [27]. 
бентом происходит за счет ван-дерваальсовых сил и водородной связи, обусловленной наличием карбоксильной группы ИБ и АУ). Оптимальные условия сорбции [27, 31, 43, 44, 46], полученные с помощью математического моделирования, приведены в табл. 1. Более подробно влияние условий пиролиза, активации и модификации на физикохимические свойства БУ и их адсорбционную способность представлены в обзорных статьях [60-62].

\section{Сорбция материалами на основе графена, углеродных нанотрубок и других материалов на основе углерода}

Графены, благодаря своим электрическим и оптическим свойствам, а также химической или физической стабильности, вызывают огромный интерес исследователей в области наноэлектроники, суперконденсаторов, топливных элементов, аккумуляторов, фотоэлектрической энергии, катализа, сорбции газов. Кроме того, графены являются перспективными сорбентами [63-65].

Нитрид углерода $\left(\mathrm{C}_{3} \mathrm{~N}_{4}\right)$, характеризующийся большой площадью поверхности, превосходной химической и термической стабильностью, применяется в качестве сорбента различных классов веществ [66]. Сорбирующий композит $\mathrm{C}_{3} \mathrm{~N}_{4} /$ сажа, получают одностадийным пиролизом угля при $500^{\circ} \mathrm{C}$ и применяют для сорбции ИБ [67]. Механизм сорбции интерпретирован донорно-акцепторными взаимодействиями, а именно взаимодействиями электрона-акцептора ароматического кольца ИБ и электронадонора поверхностных карбонильных групп сорбата. Кроме того, ИБ и композит могут образовывать поверхностные комплексы ввиду присутствия - $\mathrm{COOH}$ групп в ИБ и -ОН групп композита. Добавление $\mathrm{C}_{3} \mathrm{~N}_{4}$ к саже увеличивает удельную площадь поверхности с 8.72 (сажа) и $13.11\left(\mathrm{C}_{3} \mathrm{~N}_{4}\right)$ до $60.58 \mathrm{~m}^{2} / г$, поэтому композит (ввиду многочисленных сорбционных центров) характеризуется большей сорбционной активностью, по сравнению с чистыми материалами (при достижении равновесия в течение 120 мин адсорбционная емкость составляет $131 \mathrm{мг/Г).}$

Изучена сорбция АК из водного раствора графеноподобным нитридом углерода. Установлено влияние $\mathrm{pH}$, температуры, времени и степени деструкции сорбента при видимом свете. Процесс сорбции эндотермический. Сорбционное равновесие достигается за 90 мин, предельная сорбция составляет 21.27 мг/г [68].

ИБ из водных растворов сорбируют оксидом графена (ОГ), полученного окислением графена перманганатом калия в присутствии серной кислоты [69]. Сорбция описывается уравнением Ленгмюра, а кинетика - уравнением псевдо-второго порядка. В оптимальных условиях ( $t=60$ мин, $m / V=0.125 \quad \Gamma /$ дм $\left.^{3}\right)$ предельная сорбция составляет 3.72 мг/г, степень извлечения достигает $100 \%$. ОГ модифицируют в течение 10 мин при обработке ультразвуком разной мощности (24 и 12 Вт) и применяют для сорбции ДК [70]. Изотермы сорбции описывают уравнением Фрейндлиха. При сорбции в течение 24 ч, $\mathrm{pH} 7$ и $20^{\circ} \mathrm{C}$ предельная сорбция модифицированного образца на $10 \%$ выше, чем при применении исходного ОГ.

Карбоксилированные и некарбоксилированные многослойные углеродные нанотрубки применяют для сорбции ИБ из кислых растворов в статических [71] и динамических условиях [72]. Углеродные нанотрубки (УНТ) модифицируют наночастицами металлов, например, $\mathrm{Ag}$, полученными из раствора $\mathrm{Na}_{2} \mathrm{HPO}_{4}$ с $\mathrm{AgNO}_{3}$. Новый материал характеризуется высокой фотокаталитической активностью и способен сорбировать ДК из водных сред (предельная сорбция составляет 9.470 мг/г). Предложены способы соосаждения и гидротермального синтеза наноразмерных частиц $\mathrm{Fe}$ и применения их для модификации УНТ [73]. В результате получены магнитные сорбенты различных размеров Fе и УНТ 
с разными соотношениями. Композиты применены для сорбции ДК и ИБ из водных сред. Величина предельной сорбции на лучшем образце (размер частиц $\mathrm{Fe}-60$ нм, УНТ - 100 нм, соотношение 1:1) составляет соответственно 17.9 и $9.0 \mathrm{мг/ \Gamma ,} \mathrm{равновесие} \mathrm{устанавлива-}$ ется за 30 мин [73]. При модифицировании графена азотной кислотой увеличивается число $-\mathrm{OH}$ и $-\mathrm{COOH}$ на поверхности сорбента, удельная площадь поверхности (с 122.7 до $129.7 \mathrm{~m}^{2} / \Gamma$ ), суммарный объем пор (с 0.438 до $1.657 \mathrm{~cm}^{3} / \Gamma$ ) и, как следствие, более чем в 2.5 раза предельная сорбция ДК по сравнению с исходным графеном [74]. Czech В. и др. [75] обрабатывали УНТ 0.35\% раствором $\mathrm{H}_{2} \mathrm{O}_{2}$ и ультрафиолетовым излучением (5 ч, 254 нм, мощность потока 15 Вт). Для описания сорбции ИБ полученными образцами УНТ (предельная сорбция соответственно составляет 2488.8 и 1552.4 дм³ $^{3} /$ ) применены модели Фрейндлиха, Ленгмюра, Темкина, ДубининаРадушкевича. Наилучшая аппроксимация достигается при применении моделей Фрейндлиха или Ленгмюра.

Хитозан (ХT) - один из наиболее распространенных катионных полисахаридов, состоящий из случайно распределенных (1-4)-связанных 2-амино-2дезокси- $\beta$-D-глюкопиранозных звеньев. Этот линейный биополимер получают деацетилированием XТ, основного компонента экзоскелетов ракообразных [76]. Синтезирован магнитный композит на основе ХT, функционализированный амином и $\mathrm{Fe}_{3} \mathrm{O}_{4}$ [77], и модифицированный измельченной крошкой каучука [78]. Предельная сорбция ДК составляет 196 [77] и 17.7 мг/г [78]. Сорбция композитом, полученным в работе [77], происходит за счет электростатического притяжения между положительно заряженными полимерными цепями - одинарной связью $\mathrm{N}^{+}\left(\mathrm{CH}_{3}\right)_{3}$ и анионами сорбата.

\section{Сорбция сорбентами на основе кремнезема и наноструктурированными кремниевыми материалами}

Наноструктурированные кремниевые материалы экономически эффективны, характеризуются мезопористой структурой и высокой площадью поверхности. Для их модифицирования применяют катионные поверхностно-активные вещества (ПАВ), которые увеличивают расстояние между слоями, что приводит к увеличению сорбционной способности [79].

Кремнезем модифицируют ПАВ с различными алкильными цепями: $\left[\mathrm{C}_{16} \mathrm{H}_{33}-\mathrm{N}^{+}\left(\mathrm{CH}_{3}\right)_{2}-\mathrm{CH}_{2}\right]_{2} \cdot 2 \mathrm{Br}^{-}\left(\mathrm{G}_{16-2-16}\right)$, $\left[\mathrm{C}_{12} \mathrm{H}_{25}-\mathrm{N}^{+}\left(\mathrm{CH}_{3}\right)_{2}-\mathrm{CH}_{2}\right]_{2} \cdot 2 \mathrm{Br}^{-}\left(\mathrm{G}_{12-2-12}\right)$, и $\left[\mathrm{C}_{8} \mathrm{H}_{17}-\mathrm{N}^{+}\left(\mathrm{CH}_{3}\right)_{2}-\mathrm{CH}_{2}\right]_{2} \cdot 2 \mathrm{Br}^{-}\left(\mathrm{G}_{8-2-8}\right)$.

Установлена оптимальная концентрация модификатора $\mathrm{G}_{16-2-16}, \mathrm{G}_{12-2-12}$ и $\mathrm{G}_{8-2-8}-$ $0.23,0.14$ и 0.09 ммоль на 1 г кремнезема. Полученный органоматериал (SiNSs) характеризуется быстрым установлением сорбционного равновесия (5 мин) и высокой сорбционной активностью (64.19 мг/г) к ИБ при концентрации ПАВ 0.42 ммоль/г. Такие характеристики обусловлены электростатическим взаимодействием и эффектом электрического заряда (partition effect plays). Чем длиннее алкильная цепь, тем больше предельная сорбция ИБ. Сорбционные способности трех материалов уменьшаются в ряду $\mathrm{G}_{16-2-16-\mathrm{SiNSs}}(64.19 \mathrm{MГ} / \Gamma)>$ $>\mathrm{G}_{2-2-12-\mathrm{SiNSs}}(40.14 \quad \mathrm{M} / \Gamma)>\mathrm{G}_{8-2-8}-\mathrm{SiNSS}$ $(4.84 \mathrm{M \Gamma} / \Gamma)$ [80].

Из пемзы получен кремнеземный аэрогель, который применен в качестве эффективного сорбента для извлечения ИБ [81]. С использованием неполярного растворителя и тетраэтилортосиликата на поверхность аэрогеля привит многослойный материал, содержащий аминные группы. Изучение морфологии модифицированного материала показало наличие аморфных фаз, однородных сферических частиц, содержащих кремнезем, с размером менее 25 нм и удельной поверхностью $407 \mathrm{~m}^{2} / \Gamma$. Гид- 
рофобные, электростатические и неэлектростатические взаимодействия обусловливают механизм сорбции ИБ. При pH 7, исходной концентрации ИБ 6.53 мг/дм³ содержании сорбента 0.5 г/дм ${ }^{3}$ достигается $100 \%$ извлечение ИБ в течение 150 мин.

Мезопористые материалы с гексональной (МСМ-41 и SBA-15) [5, 82, 83], трехмерной (МСM-48) [83] и пенообразной (TUD-1) мезопористой структурой применяют в основном для адресной доставки НПВС [84]. В работе [85] мезопористые кремнеземы SBA-15 (шестиугольный) и КIT-6 (кубический), полученные гидротермальным методом, с использованием в качестве шаблона триблочного сополимера Pluronic P123 [86], модифицировали водным раствором хлорида лантана (III). При изменении массовой доли соли от 1 до 5\% мас. увеличивается сорбция ИБ (следствие увеличения среднего диаметра пор сорбента). Количество ИБ, сорбированного KIT-6, модифицированного лантаном, на $13 \%$ выше, чем на материалах SBA-15.

Для химической модификации материалов на основе кремнезема применены ионные жидкости, содержащие катион 1-метил-3-пропилимидазолия в сочетании с шестью анионами [87]. На рис. 3а приведена принципиальная схема синтеза [Si] $\left[\mathrm{C}_{3} \mathrm{C}_{1} \mathrm{im}\right] \mathrm{Cl}$. [Si] $\left[\mathrm{C}_{3} \mathrm{C}_{1} \mathrm{im}\right][\mathrm{SCN}$, $[\mathrm{Si}] \quad\left[\mathrm{C}_{3} \mathrm{C}_{1} \mathrm{im}\right] \quad\left[\mathrm{N}(\mathrm{CN})_{2}\right], \quad[\mathrm{Si}] \quad\left[\mathrm{C}_{3} \mathrm{C}_{1} \mathrm{im}\right]$ [Tos], [Si] [ $\mathrm{C}_{3} \mathrm{C}_{1} \mathrm{im}$ ] [Male] и [Si] $\left[\mathrm{C}_{3} \mathrm{C}_{1} \mathrm{im}\right]$ [NTf $\left.{ }_{2}\right]$, полученные анионным обменом из $[\mathrm{Si}]\left[\mathrm{C}_{3} \mathrm{C}_{1} \mathrm{im}\right] \mathrm{C}_{1}$ по реакциям, приве-

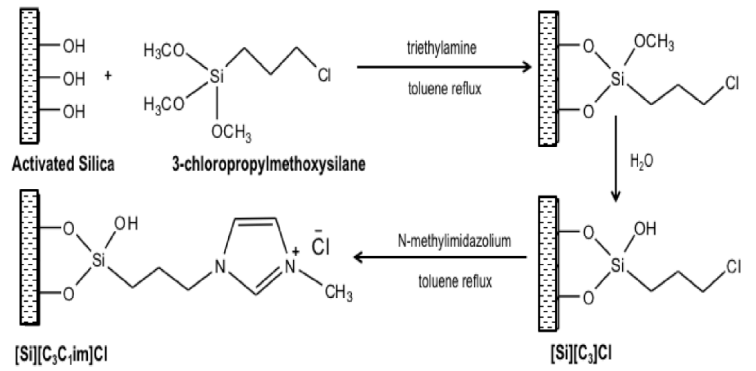

a денным на рис. 3б. Для описания стадии регулирования скорости, влияющей на сорбцию, выбраны модели пленочной диффузии Бойда и диффузии пор Уэббера. Максимальная равновесная концентрация ДК составляет 0.74 ммоль (0.235 г) в расчете на 1 г адсорбента, равновесие достигается за 60 мин. Регенерацию сорбента проводят смесью бутанола-1 и воды $(85: 15$, об.).

\section{Сорбция природными глинистыми материалами}

В последние годы глинистые материалы (ГМ), а также наногетероструктуры на основе ГМ, привлекают внимание многих исследователей в связи с их высоким влагопоглощением (набуханием), а также высокой катионообменной емкостью [88].

Изучена сорбция ИБ, напроксена и карбамазепина на ГМ из месторождения JbelSejnane (Турция), которую предварительно очищали и перемешивали с раствором $\mathrm{NaCl}$ для получения гомогенной Na-глины [89]. Установлено, что сорбция фармацевтических препаратов является спонтанным, эндотермическим процессом [90]. ИБ, ДК, индометацин, хлорфенираминмалеат и парацетамол из водных растворов сорбируют природным иорданским цеолитом [91]. ДК извлекается при $\mathrm{pH}$ 6, остальные сорбаты при рН 2, время сорбции 80 мин. Степень извлечения возрастает с увеличением начальной концентрации препаратов с 10.0 до $50.0 \mathrm{M \Gamma} / \mathrm{дM}^{3}$.

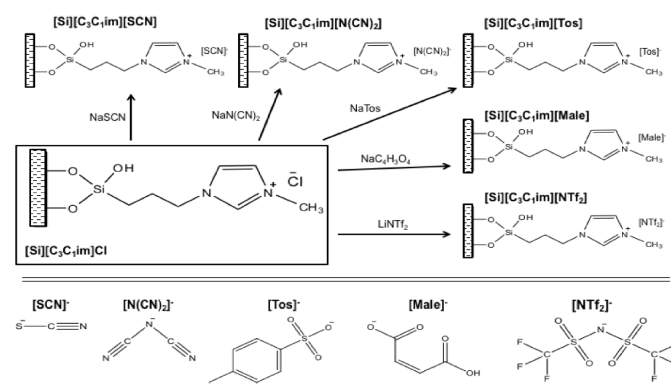

6

Рис. 3. Схемы получения кремниевого материала на основе ионной жидкости [Si] $\left[\mathrm{C}_{3} \mathrm{C}_{1} \mathrm{im}\right] \mathrm{Cl}$ (а) и его модифицирование шестью анионами (б) [87].

Fig. 3. Schemes for obtaining silicon material based on ionic liquid $[\mathrm{Si}]\left[\mathrm{C}_{3} \mathrm{C}_{1} \mathrm{im}\right] \mathrm{Cl}$ (a) and its modification with six anions (b) [87]. 
В выбранных условиях извлекается $88.3,30.1,59.0,85.8$, и 12.7\% ИБ, ДК, индометацина, хлорфенираминмалеата и парацетамола соответственно. Предельная сорбция 4.8 и 26.6 мг/Г соответственно ИБ и ДК. Используемый материал регенерируют 9 раз.

При приготовлении ГМ возникают проблемы с диспергированием и проникновением макромолекул в пространство между силикатными пластинами, что приводит к низким степеням извлечения сорбатов. Степень извлечения повышается при модификации поверхности глин ПАВ, в которых число углеродных атомов изменяется от 6 до 20 [92].

Природный монтмориллонит $\left(\mathrm{C}_{18}-\mathrm{Mt}\right)$ и синтетическую слюду ( $\mathrm{C}_{18}$-mica-4) модифицируют по реакции катионного обмена с октадециламином [93]. Включение ИБ в глины изучено методом XRDанализа и измерением дзета-потенциала поверхности. Изотерма сорбции описана моделями Ленгмюра, Фрейндлиха и Дубинина-Радушкевича. Скорость сорбции $\mathrm{C}_{18}$-Mt (99.9\%) не зависит от концентрации ИБ в диапазоне 0.1-80 мг/дм ${ }^{3}$. Кинетика сорбции оценена с использованием моделей псевдо-первого и псевдовторого порядков, внутричастичной диффузии и модели Еловича. Кинетическая модель псевдо-второго порядка наиболее адекватно описывает сорбцию ИБ $\left(\mathrm{R}^{2}>0.993\right)$. Равновесие достигается менее чем за 5 и 60 мин при применении $\mathrm{C}_{18}$-Mt и $\mathrm{C}_{18}$-mica-4 соответственно.

Для модифицирования влажного бентонита применен бромид цетилтриметиламмония с различными концентрациями $(0.5,1$ и 2 СЕС). Эффективность сорбентов изучена на примере сорбции ДК и ИБ из водного раствора. Кинетика сорбции описана кинетической моделью псевдо-первого порядка. Изотерма сорбции описана моделями Ленгмюра и Фрейндлиха с предельной сорбцией 600.6 и 194.9 мг/г для ДК и ИБ соответственно [94]. По аналогии [94] с применением бромида гексадецилтриметиламмония получен гибридный материал, который пилларируется алюминием (раствор глины смешивают с хлоридом алюминия, перемешивают 5 ч, выдерживают 2 суток). Установлено влияние $\mathrm{pH}$ раствора (3.8-10.0), концентрации сорбата (1.0-20.0 мг/дм $\left.{ }^{3}\right)$ и фонового электролита (0.0001-0.1 моль/дм $\left.{ }^{3} \mathrm{NaCl}\right)$. Кинетика поглощения ДК этими твердыми сорбентами описана нелинейными уравнениями скорости псевдо-первого и псевдо-второго порядков [95].

Синтезирована [96] цеолитносепиолитовая наногетероструктура (ZeoSep) и модифицированный органосепиолит (сепиолит - природный гидратированный минерал из силиката магния и глины с микроволокнистой морфологией и хорошими сорбционными свойствами [97]), которые использованы для сорбции ИБ из водного раствора. Для интерпретации механизма на молекулярном уровне выбраны хемометрические модели. Сорбция ИБ обусловлена образованием двух слоев и происходит по горизонтальной и не горизонтальной плоскости сорбента. При $60^{\circ} \mathrm{C}$ число захваченных молекул ИБ составляет около двух, т.е. в растворе образуются димеры (физический механизм сорбции).

В работе [98] ИБ сорбировали с использованием наногетероструктуры на основе клоизита 15A, ПВП и $\beta$ циклодекстрина (CD@clay-PVP). Свойства химически модифицированной наноглины изучают ИК-спектроскопией с преобразованием Фурье, сканирующей электронной микроскопией и с применением XRD-анализа. Схема синтеза приведена на рис. 4. Наноглинистый композит на основе алюминосиликатного минерала Cloisite15A [99] использован для сорбции ИБ. Изучено влияние $\mathrm{pH}$ (5-9), начальных концентраций сорбата $(3,5$ и $10 \mathrm{мг} /$ дм $\left.^{3}\right)$, времени контакта фаз и количество сорбента (0.125-1 г) на степень извлечения ИБ. При рН 6 равновесие достигается за 120 мин, степень извлечения составляет 95.2\%. Изотермы сорбции аппроксимированы моделями Фрейндлиха, Фрица-Шлундера, Редлиха- 


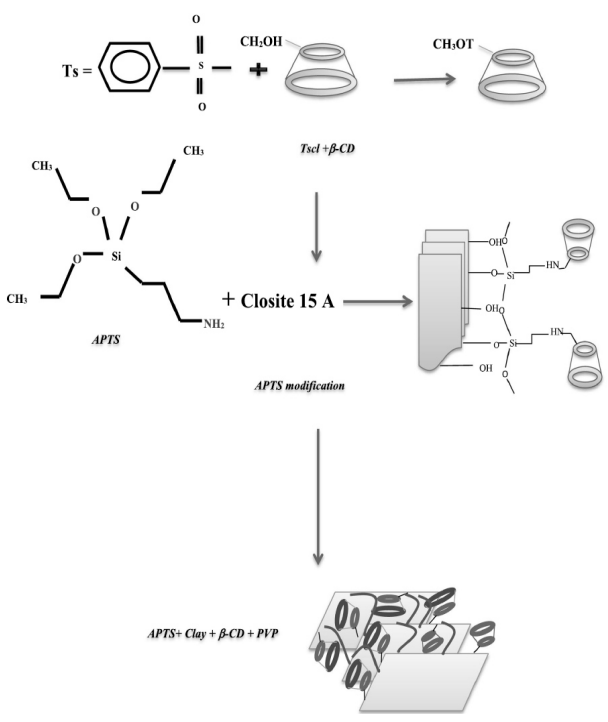

Рис. 4. Приготовление наногетероструктуры на основе клоизита [98].

Fig. 4. Preparation of a nanoheterostructure based on cloisite [98].

Петерсона, Радке-Праусница, Сипа, Тота и Хана.

Активированные плазмой цеолиты используются для извлечения ДК из водного раствора. Природные цеолиты подвергают воздействию радиочастотного плазменного разряда 13.56 МГц в среде аргона. Сорбционная емкость цеолитов возрастает до 64\% при использовании плазменно-обработанных по сравнению с необработанными цеолитами $(52 \%)$. Такой эффект после обработки обусловлен увеличением поверхностной пористости за счет травления и абляционных эффектов. Изотерма сорбции ДК описана моделью Фрейндлиха [100].

В статическом режиме изучена сорбция ДК органоглиной марки Spectrogel Туре С. Условия сорбции оптимизированы с использованием математического моделирования (CCD). Выбраны масса сорбента $(0.5$ г) и скорость перемешивания раствора (200 об/мин). Модель псевдо-первого порядка показала наилучшую корреляцию с кинетическими экспериментальными данными, основным этапом регулирования скорости является внешний массоперенос. При 15 и $30^{\circ} \mathrm{C}$ сорбция описывается изотермой Фрейндлиха. Максимальная сорбционная емкость составляет $42.3 \mathrm{мг/ \Gamma} \mathrm{[101].}$

Помимо традиционного применения природные сорбенты могут применятся для адресной доставки лекарств (например, материал на основе нанотрубок галлоизита [102, 103]), а также - окислительных процессов (гетерогенный катализатор типа Фентона, полученный методом твердотельного ионного обмена [104]) при очистке НПВС.

\section{Сорбция полимерными сорбентами}

Полимеры применяют для сорбции многих классов органических соединений, например, растительных веществ (сапонины) [105], БАДов [106], ароматических кислот [107, 108], фенолов [109, 110] и других.

Установлены кинетические и термодинамические параметры сорбции АК с применением нанокомпозитных полимеров $(\mathrm{N}-\mathrm{CNT} / \beta-\mathrm{CD}$ и $\mathrm{Fe} / \mathrm{N}-\mathrm{CNT} / \beta-\mathrm{CD})$, полученных на основе нанотрубок, активированных азотом (N-CNT), циклодекстрина $(\beta-\mathrm{CD})$ и наночастиц Fe. Полимеры получают с помощью метода СВЧ-ассистированного синтеза нанокомпозитов и исследуют различными физико-химическими методами. Максимальная сорбционная емкость АК составляет 71.9 и 101.0 мг/г соответственно. Кинетика сорбции на сорбентах N$\mathrm{CNT} / \beta-\mathrm{CD}$ и $\mathrm{Fe} / \mathrm{N}-\mathrm{CNT} / \beta-\mathrm{CD}$ описываетcя кинетическими моделями псевдовторого порядка и Еловича [111]. 
Для сорбции АК из водных сред применяют молекулярно импринтированные полимеры (МИП) [112]. Основные преимущества МИП состоят в простом синтезе и возможности создания селективных сорбентов для конкретного сорбата [113]. Для синтеза применяют молекулу шаблон, функциональный мономер (метакриловая кислота) и сшивающий агент (этиленгликольдиметакрилат). Продемонстрирована возможность повторного использования МИП после регенерации. Аналогично синтезирован сорбент, который применяют для извлечения ИБ из лекарственных средств [114].

Селективное удаление фармацевтических препаратов из водных сред с помощью МИП предложено в работе [115]. Выбраны параметры сорбции напроксена, ИБ и ДК, обеспечивающие наибольшую степень их извлечения: масса МИП - 50 мг, время контакта фаз - 10 мин, $\mathrm{pH}$ 4.6. Коэффициенты импринтинга, полученные для напроксена, ИБ и ДК, составили $1.25,1.42$ и 2.01 соответственно. Кинетика сорбции описана моделью псевдо-второго порядка. Степень извлечения напроксена, ИБ и ДК составила 38, 69 и 87\% соответственно. Методами преципитации МИП синтезировали на поверхности многостенных углеродных нанотрубок с использованием 2-фенилпропионовой кислоты в качестве фиктивной матрицы, 4-винилпиридина, диметакрилата этиленгликоля, ДМФА в качестве функционального мономера, сшивающего агента, и порогена соответственно. МИП характеризуется хорошими селективными и адсорбционными свойствами для пяти нестероидных противовоспалительных препаратов 2фенилпропионовой кислоты [116]. Двойной импринтинг является основополагающим для улучшения адсорбционной способности МИП, но влияние типа ПАВ на сорбционные свойства полимеров изучено недостаточно. Da Silva c соавторами проведена модификация МИП хлоридом бензалкония (ВС), додецилсульфатом натрия (SDS) и Тритона
X-100 (ТT-X-100). Полученные сорбенты МИП-ВС, МИП-SDS, МИП-ТТ-Х-100 применены для сорбции ДК. Кинетические исследования, проведенные при $\mathrm{pH}$ 6, показали наилучшую апроксимацию $\left(\mathrm{R}^{2}=0.999\right)$ с использованием модели псевдо-второго порядка (время достижения равновесия 45 с). Добавление ПАВ увеличивает адсорбционные свойства материала в сравнении с немодифицированным МИП (0.42 мг/г). Так, МИП-ВС характеризуется лучшей адсорбционной емкостью (1.82 мг/ г), по сравнению с МИП-SDS (1.12 мг/г) и МИП-ТТ-Х-100 (0.51 мг/г). При добавлении к МИП поверхностно-активного вещества увеличивается размер пор и, как следствие, увеличиваются сорбционные свойства материала [117].

Суспензионно-эмульсионной полимеризацией синтезирован сшитый полимер на основе поли(триметилолпропанатриметакрилата) и 2-гидроксиэтилметакрилата. Степень извлечения ИБ более $95 \%$ при времени достижения равновесия 20 ч [118]. Синтезированы и применены для сорбции ДК из водных растворов гибридные полимерные материалы AAS (Al-AMBA-sericite) и AHS (Al-HDTMAsericite) [119]. При увеличении концен-

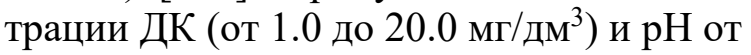
2 до 7 степень извлечения возрастает. Фоновые концентрации электролитов (0.0001 до 0.1 моль/дм $\left.{ }^{3} \mathrm{NaCl}\right)$ незначительно влияют на степень извлечения ДК. Кинетика сорбции описывается уравнением Томаса.

Популярными сорбентами для извлечения различных классов соединений являются магнитные наночастицы, которые легко отделяются от раствора анализируемого образца магнитом без необходимости его фильтрации или центрифугирования, а также обеспечивается быстрое время достижения равновесия [120]. Для сорбции ИБ [120] методом суспензионной полимеризации получена серия магнитных сорбентов (ND-1, ND-2 и ND-3) с различной структурой пор, благодаря использованию определен- 


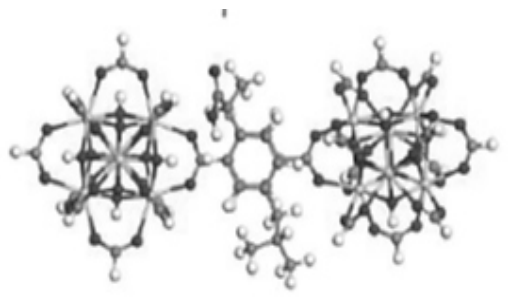

a)

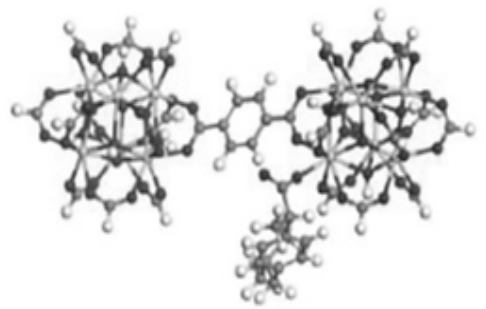

в)

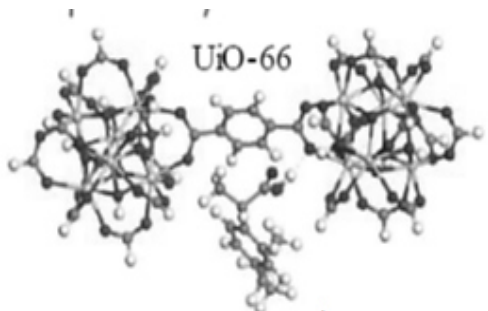

б)

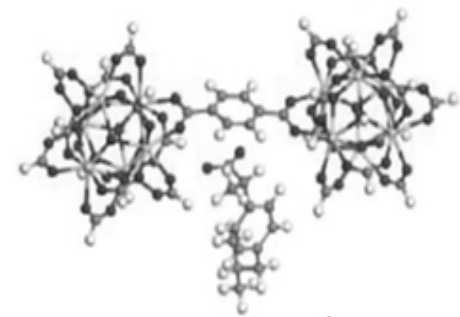

г)

Рис. 5. Возможные механизмы [ $\pi-\pi$-взаимодействия (а), водородная связь (б) комплексообразование - кислота Льюиса/основание (в), анион- $\pi$ взаимодействие (г)] сорбции ДК сорбентом UiO-66 [124].

Fig. 5. Possible mechanisms of [ $\pi-\pi$ EDA interaction (a), hydrogen bond (b) Lewis $\mathrm{acid} /$ base complexing (c), anion- $\pi$ interaction (d)] of DC sorption by the UiO-66 sorbent [124].

ного количества циклогексанола в качестве порогена $(30,50,80 \%)$. Предельная сорбция для материалов ND-1, ND-2 и ND-3 составляет соответственно 0.18, 0.23 и 0.21 ммоль/г.

Поверхность наночастиц $\mathrm{Fe}_{3} \mathrm{O}_{4}$ модифицируют бромидом цетилтриметиламмония (ЦТАБ). Сорбент применен для сорбции ИБ. Оценены и оптимизированы дзета-потенциал наночастиц, количество ПАВ, $\mathrm{pH}$, условия десорбции, время сорбции и десорбции, объем образца и ионная сила. Сорбенты позволяют селективно и извлекать 96-99\% ИБ из водных сред [122]. Предложен способ извлечения ИБ, ДК и сульфадиазина магнитными полимерными сорбентами, полученными суспензионной полимериза- цией метилакрилата, дивинилбензола в присутствии перекиси бензоила, частиц $\mathrm{Fe}_{3} \mathrm{O}_{4}$, желатина и $\mathrm{NaCl}$ в качестве дисперсионной фазы [123].

Металлоорганические каркасы (metal organic framework, MOF) привлекли внимание исследователей, как перспективные материалы для сорбции. MOF отличаются большой площадью поверхности, высокой термостойкостью и большим объемом пор [124]. Исследована сорбция ИБ двумя типами MOF UiO66 и UiO-66- $\mathrm{NH}_{2}$. Четыре механизма ( $\pi$ - $\pi$-взаимодействия, комплексообразование - кислота Льюиса/основание, водородная связь и анион- $\pi$ взаимодействие) одновременно обусловливают сорбцию ИБ (рис. 5). Предельная сорб-

Таблица 2. Сорбция НПВС металлоорганическими каркасами различной структуры Table 2. Sorption of NSAIDs by metalorganic frameworks of various structures

\begin{tabular}{|c|c|c|c|}
\hline Сорбат & Сорбент & $\mathrm{a}_{\mathrm{p}}, \mathrm{M \Gamma} / \Gamma$ & Литература \\
\hline \multirow{5}{*}{ ИБ } & $\begin{array}{c}\mathrm{UiO}-66 \\
18 \% \mathrm{SO}_{3} \mathrm{H}-\mathrm{UiO}-66\end{array}$ & $\begin{array}{l}189 \\
263\end{array}$ & [125] \\
\hline & $\begin{array}{l}\mathrm{UiO}-66-\mathrm{NH}_{2}(25) \\
\mathrm{UiO}-66-\mathrm{NH}_{2}(90)\end{array}$ & $\begin{array}{l}357 \\
555 \\
\end{array}$ & [126] \\
\hline & $\begin{array}{c}\text { ZIF-8 } \\
\text { PCDM-1000 }\end{array}$ & $\begin{array}{l}105 \\
393\end{array}$ & [127] \\
\hline & {$\left[(\mathrm{CH} 3) 2 \mathrm{NH}_{2}\right]\left\{\left[\mathrm{Cu} 2(\mathrm{~L}) \cdot\left(\mathrm{H}_{2} \mathrm{O}\right)_{2}\right] . x\right.$ solvent $\} \mathrm{n}$} & 490 & [128] \\
\hline & [Cu(BTTA)]n.2DMF & 650 & [129] \\
\hline$\overline{\mathrm{AK}}$ & MIL-100 (Fe) & 125 & [130] \\
\hline
\end{tabular}


ция ДК, изученными MOF, варьируется от 125 до 650 мг/г (табл. 2). Магнитный наноматериал с покрытием из 3глицидилоксипропилтриметоксисилана, модифицированный L-цистеином, обеспечивает максимальное извлечение $(82.9 \%)$ ДК при массе сорбента - 30 мг, начальной концентрации $50 \mathrm{мг} /$ дм $^{3}$ и $\mathrm{pH}$ 6.0. Кинетика сорбции соответствует реакции псевдо-второго порядка и изотерме сорбции Ленгмюра [131]. Синтезированный магнитный гибридный наносорбент $\mathrm{Fe}_{3} \mathrm{O}_{4} / \mathrm{GO} / \mathrm{CdSe}$ применен для твердофазной экстракции ИБ из фармацевтических препаратов, воды и мочи. Материал охарактеризован методами рентгеновской дифракции, Рамановской спектроскопии и сканирующей электронной микроскопии. Выбраны условия сорбции ( $\mathrm{pH}$, объем раствора, количество сорбента, тип и объем элюирующего растворителя, время экстракции). Извлечение ИБ составляет от 87 до 109\% [132].

\section{Заключение}

Анализ сорбентов, применяемых для сорбции НПВС, показывает, что для концентрирования широкое применение нашли органо-неорганические полимерные композиционные материалы на основе природных глин (бентонит, монтмориллонит, вермикулиты), коммерческие гранулированные активные угли, биоугли, полимерные сорбенты природного и синтетического происхождения (МИП, металлорганические полимеры). Для улучшения сорбционных характеристик предложено применять методы термической и химической активации сорбентов, а также модифицировать их наноматериалами (наночастицы, графен и его производные) и органическими соединениями (ПАВ, метакриловая кислота и т.д.). Материалы на основе природных глин обладают преимуществами по сравнению с другими материалами, а именно благодаря своей доступности, легкости модификации их можно применять для сорбции НПВС.

\title{
The use of sorbents of various natures for the extraction of non-steroidal anti-inflammatory drugs from aqueous media (review)
}

\author{
(C) 2021 Kushnir A.A. ${ }^{1}$, Sypko K.S. ${ }^{2}$, Gubin A.S. ${ }^{1}$, \\ Sheremet E.O. ${ }^{1}$, Sukhanov P.T. ${ }^{1}$ \\ ${ }^{1}$ Voronezh State University of Engineering Technologies, Voronezh, Russian Federation \\ ${ }^{2}$ Nevinnomyssk Institute of Technology (branch) of the "North-Caucasus Federal University", Nevinnomyssk, \\ Russian Federation
}

Non-steroidal anti-inflammatory drugs (NSAIDs) belong to the group of anti-inflammatory, analgesic, and antipyretic drugs and are among the most consumed pharmaceuticals by the global population. NSAIDs are characterised by side effects and biodegrade in the environment with the formation of the not less toxic compounds. Determination of non-steroidal anti-inflammatory drugs at the level of microconcentrations, even with the use of sensitive methods of analysis, is possible only after preliminary concentration.

The purpose of this study was to summarize the use of sorbents of various natures (including those of natural origin) for the sorption of non-steroidal anti-inflammatory drugs based on international databases.

Active carbons, biochar, materials based on graphene, carboxylated and uncarboxylated multilayer carbon nanotubes and other materials based on carbon (graphene-like carbon nitride, graphene oxide, chitosan, carbon nitride) are widely used for concentration. Nanostructured silicon and clay materials (CM), as well as nanoheterostructures based on CM are cost-effective, characterized by a mesoporous structure and a high surface area. For their modification, cationic surfactants and ionic liquids are used. In order to obtain a more developed surface and increase in the number of functional groups, it was proposed to activate sorbents by physical (thermal activation in a stream of gases) or chemical (use of inorganic acids, salts and alkalis) 
methods. Molecularly imprinted polymers were synthesized by precipitation and double imprinting processes, and crosslinked polymers and hybrid polymeric materials were synthesized by suspension-emulsion polymerization. Popular sorbents for the recovery of NSAIDs are magnetic nanosorbents and organometallic polymers.

The review presents the sorption conditions ( $\mathrm{pH}$, solution volume, time to reach sorption equilibrium, sorbent mass), chemometric algorithms for optimizing the sorption conditions and the values of the limiting sorption of diclofenac, ibuprofen, and acetylsalicylic acid by materials of various natures. Possible sorption mechanisms, kinetic and sorption models, are described.

Keywords: non-steroidal anti-inflammatory drugs, sorption, activated carbons, biochar, natural sorbents, carbon materials, polymer sorbents.

\section{Список литературы/References}

1. WangJ., WangS., J. Environ. Manage., 2016, Vol. 182, pp 620-640. DOI: 10.1016/j.jenvman.2016.07.049.

2. Bai X., Acharya K., Sci. Total Environ., 2017, Vol. 581-582, pp. 734-740. DOI: 10.1016/j.scitotenv.2016.12.192.

3. Marta Z., Bobaly B., Fekete J., Magda B. et al., J. Pharm. Biomed. Anal., 2018, Vol.160, pp. 99-108 doi.org/10.1016/j.scitotenv.2016. 12.192

4. Nikolaou A., Meric, S., Fatta D., Anal. Bioanal. Chem., 2007, Vol. 387, No 4, pp. 12251234. DOI:10.1007/s00216-006-1035-8

5. Bonnefille B., Gomez E., Courant F., Escande A. et al., Mar. Pollut. Bull., 2018, Vol. 131, pp. 496-506. DOI: 10.1016/j.marpolbul. 2018.04.053.

6. Sousa J.C.G., Ribeiro A.R., Barbosa M.O., Pereira M.F.R. et al., J. Hazard. Mater., 2018, Vol. 344, pp. 146-162. DOI: 10.1016/j.jhazmat.2017.09.058.

7. Rigobello E.S., Dantas A.D.B., Di Bernardo L., Vieira E.M., Chemosphere, 2013, Vol. 92, pp. 184-191. DOI: 10.1016/j.chemosphere. 2013.03.010.

8. Schwaiger J., Ferling H., Mallow U., Wintermayr H. et al., Aquat. Toxicol., 2004, Vol. 68, pp. 141-150. DOI: 10.1016/j.aquatox.2004. 03.014

9. Mehinto A.C., Hill E.M., Tyler C.R., Environ. Sci. Technol., 2010, Vol. 44, No 6, pp. 2176-2182. DOI:10.1021/es903702m.

10. Näslund J., Fick J., Asker N., Ekman E., Larsson D.G.J., Norrgren L., Aquat. Toxicol., 2017, Vol. 189, pp. 87-96. DOI: 10.1016/ j.aquatox.2017.05.017.

11.Gunnarsson L., Jauhiainen A., Kristiansson E., Nerman O. et al., Environ. Sci. Technol., 2008, Vol. 42, pp. 5807-5813.DOI: 10.1021/ es8005173.

12. Nieto-Sandoval J., Munoz M., de Pedro Z.M., Casas J.A., Chemosphere, 2018, Vol.
213, pp. 141-148. DOI: 10.1016/j.chemosphere. 2018.09.024.

13. Martínez C., Canle L., Fernández M.I., Santaballa J.A., Faria J., Applied Catalysis B: Environmental, 2011, Vol. 107, No 1-2, pp. 110-118. DOI: 10.1016/j.apcatb.2011.07.003.

14. Barenboim G.M., Chiganova M.A., Chemistry and Ecology, 2012, Vol. 10, pp. 40-46.

15. Nisar J., Sayed M., Khan F.U., Khan H.M. et al., J. Environ. Chem. Eng., 2016, Vol. 4, No 2 , pp. 2573-2584. DOI:10.1016/j.jece. 2016.04.034.

16. Vella K., Commission Implementing Decision (EU) 2015/495, 2015.

17. Zhou J.L, Zhang Z.L., Banks E., Grover D. et al., J. Hazard. Mater., 2009, Vol. 166, pp. 655-661. DOI: 10.1016/j.jhazmat.2008.11.070.

18. Dimitriadou S., Frontistis Z., Petala A., Bampos G. et al., Catalysis Today, 2020, Vol. 355 , pp. 937-944. DOI: 10.1016/j.cattod. 2019.02.025.

19. Schmidt S., Hoffmann H., Garbe L.-A., Schneider R.J., J. Chromatogr. A, 2018, Vol. 1538, pp. 112-116. DOI: 10.1016/j.chroma. 2018.01.037.

20. Topuz E., Sari S., Ozdemir G., Aydin E. et al., J. Chromatogr. A, 2014, Vol. 958, pp. 4854. DOI: 10.1016/j.jchromb.2014.02.047.

21. Iovino P., Canzano S., Capasso S., Erto A. et al., Chem. Eng. J., 2017, Vol. 277, pp. 360367. DOI: 10.1016/j.cej.2015.04.097.

22. Hoppen M.I., Carvalho K.Q., Ferreira R.C., Passig F.H. et al., J. Environ. Chem. Eng., 2018, Vol. 7, No 1, 102862. DOI: 10.1016/j.jece.2018.102862.

23.De Franco M.A.E., de Carvalho C.B., Bonetto M.M., de PelegriniSoares R. et al., $J$. Clean. Prod., 2018, Vol. 181, pp. 145154. DOI: 10.1016/j.jclepro.2018.01.138.

24. Rakić V., Rac V., Krmar M., Otman O. et al., J. Hazard. Mater., 2015, Vol. 282, pp. 141149. DOI: 10.1016/j.jhazmat.2014.04.062.

25.Menya E., Olupot P.W., Storz H., Lubwama M. et al., Chem. Eng. Res. Des., 2018, 
Vol. 129, pp. 271-296. DOI: 10.1016/j.cherd. 2017.11.008.

26. Jung K.-W., Choi B.H., Song K.G., Choi J.-W., Chemosphere, 2019, Vol. 215, pp. 432443. DOI: 10.1016/j.chemosphere.2018.10.069.

27. Fröhlich A.C., Ocampo-Pérez R., DiazBlancas V., Salau N.P.G., et al., Chem. Eng. J., 2018, Vol. 341, pp. 65-74. DOI: 10.1016/j.cej. 2018.02.020.

28. Fröhlich A.C., dos Reis G.S., Pavan F.A., Lima É.C. et al., Environ. Sci. Pollut. Res., 2018, Vol. 25, pp. 24713-24725. DOI:10.1007/ s11356-018-2525-x.

29. El-Shafey E.I., Ali S.N.F., Al-Busafi S., Al-Lawati H.A.J., J. Environ. Chem. Eng., 2016, Vol. 4, No 3, pp. 2713-2724. DOI: 10.1016/j.jece.2016.05.015.

30. Syeda N.F. Ali, El-Shafey E.I., Al-Busafi S., Haider A.J., J. Environ. Chem. Eng., 2019, Vol. 7, No 1, 102860, https://doi.org/ 10.1016/j.jece. 2018.102860 .

31. Sellaoui L., Guedidi H., Knani S., Reinert L. et al., Fluid Phase Equilibria, 2015, Vol. 387, pp. 103-110. DOI: 10.1016/j.fluid.2014. 12.018 .

32. Nourmoradi H., Moghadam K.F., Jafari A., Kamarehie B., J. Environ. Chem. Eng. 2018, Vol. 6, No 5, pp. 6807-6815. DOI: 10.1016/j.jece.2018.10.047.

33. Mansouri H., Carmona R.J., GomisBerenguer A. et al., J. Colloid Interface Sci., 2015, Vol. 449, pp. 252-260. DOI: 10.1016/j.jcis.2014.12.020.

34. Viotti P.V., Moreira W.M., Andreo dos Santos O.A. et al., J. Clean. Prod., 2019, Vol. 219, pp. 809-817. DOI: $10.1016 /$ j.jclepro. 2019.02.129.

35. Jodeh S., Abdelwahab F., Jaradat N., Warad I. et al., Journal of the Association of Arab Universities for Basic and Applied Sciences, 2014, Vol. 20, No 1, pp. 32-38. DOI: 10.1016/j.jaubas.2014.11.002.

36. Saucier C., Adebayo M.A., Lima E.C., Cataluña R. et al., J. Hazard. Mater., 2015, Vol. 289, pp. 18-27. DOI: 10.1016/j.jhazmat. 2015.02.026.

37. Abo El Naga A.O., El Saied M., Shaban S.A., El Kady F.Y., J. Mol. Liq., 2019, Vol. 285, pp. 9-19. DOI: 10.1016/j.molliq.2019. 04.062 .

38. Coimbra R.N., Calisto V., Ferreira C.I.A., Esteves V.I. et al., Arab. J. Chem., 2019, Vol. 12, No 8, pp. 3611-3620. DOI: 10.1016/ j.arabjc.2015.12.001.
39.Guedidi H., Lakehal I., Reinert L., Lévêque J.-M. et al, Arab. J. Chem., 2020, Vol. 13, No 1, pp 258-270. DOI: 10.1016/ j.arabjc.2017.04.006.

40. Sellaoui L., Guedidi H., Masson S., Reinert L. et al., Fluid Phase Equilibria, 2016, Vol. 414, pp. 156-163. DOI: 10.1016/j.fluid.2016.01.007.

41. Guedidi H., Reinert L., Soneda Y., Bellakhal N. et al., Arab. J. Chem., 2017, Vol. 10, pp. 3584-3594. DOI: 10.1016/j.arabjc. 2014.03.007.

42.Ondarts M., Reinert L., Guittonneau S., Baup S. et al., Chem. Eng. J., 2018, Vol. 343, pp. 163-172. DOI: 10.1016/j.cej.2018.02.062.

43. Fallou H., Cimetière N., Giraudet S., Wolbert D., et al., J. Environ. Manage., 2016, Vol. 166, pp. 544-555. DOI: 10.1016/ j.jenvman.2015.10.056.

44. Abolhasani S., Ahmadpour A., Bastami T.R., Yaqubzadeh A., J. Mol. Liq., 2019, Vol. 281, pp. 261-268. DOI: 10.1016/j.molliq. 2019.02.084.

45. Essandoh M., Kunwar B., Pittman C.U., Mohan D. et al., Chem. Eng. J., 2015, Vol. 265, pp. 219-227. DOI: 10.1016/j.cej.2014.12.006.

46. Ouasfi N., Bouzekri S., Zbair M., Ahsaine H. A., Bakkas S., Bensitel M., Khamliche L., Surfaces and Interfaces, 2019, Vol. 14, pp. 6171. DOI: 10.1016/j.surfin.2018.11.008.

47. Mphahlele K., Onyango M. S., Mhlanga S. D., J. Environ. Chem. Eng., 2015, Vol. 3, No 4, pp. 2619-2630. DOI: 10.1016/j.jece.2015. 02.018 .

48. Wong S., Lee Y., Ngadi N., Inuwa I. M. et al., Chin. J. Chem. Eng., 2018, Vol. 26, No 5, pp. 1003-1011. DOI: 10.1016/j.cjche.2017. 11.004.

49. Mukoko T., Mupa M., Guyo U., Dziike F., J. Environ. Anal. Toxicol., 2015, Vol. 7-8 pp. 19. DOI:10.4172/2161-0525.S7- 008.

50. Mondal S., Aikat K., Halder G., Ecological Engineering, 2016, Vol. 92, pp. 158172. DOI: 10.1016/j.ecoleng.2016.03.022.

51. Chakraborty P., Show S., Banerjee S., Halder G., J. Environ. Chem. Eng., 2018, Vol. 6, No. 4, pp. 5287-5300. DOI: 10.1016/j.jece. 2018.08.017.

52.Jung C., Boateng L.K., Flora J.R.V., Oh J. et al.,, Chem. Eng. J., 2015, Vol. 264, pp. 19. DOI: 10.1016/j.cej.2014.11.076.

53. Klamt A., Eckert F., Fluid Phase Equilib., 2000, Vol. 172, pp. 43-72.

54. Gil A., Taoufik N., García A.M., Korili S.A., Environmental Technology, 2019, Vol. 
40, No 23, pp. 3017-3030. DOI:10.1080/ 09593330.2018 .1464066$.

55. Huang Z., Gong B., Huang C.-P., Pan S.Y. et al., J. Environ. Chem. Eng., 2019, Vol. 231, pp. 121-128. DOI: 10.1016/j.jenvman. 2018.09.092.

56. Larous S., Meniai A.-H., International Journal of Hydrogen Energy, 2016, Vol. 41, No 24, pp. 10380-10390. DOI: 10.1016/j.ijhydene. 2016.01.096.

57. Bhadra B.N., Seo P.W., Jhung S.H., Chem. Eng. J., 2016, Vol. 301, pp. 27-34. DOI: 10.1016/j.cej.2016.04.143.

58. Sellaoui L., Mechi N., Lima É.C., Dotto G.L., et al., J. Phys. Chem. Solids., 2017, Vol. 109, pp. 117-123. DOI: 10.1016/ j.jpcs.2017.05.019.

59. Abo El Naga A.O., El Saied M., Shaban S.A., E1 Kady F.Y., J. Mol. Liq., 2019,Vol. 285, pp. 9-19. DOI: 10.1016/j.molliq.2019.04.062.

60. Abbas Z., Ali S., Rizwan M., Arab. J. Geosci., 2018, Vol. 11, pp. 448. DOI: 10.1007/ s12517-018-3790-1

61.Chaturvedi V., Clean Energy Production Technologies. Springer, Singapore., 2020, pp. 391-415. DOI: 10.1007/978-981-15-9593-6_15.

62. Ouyang J., Zhou, L., Liu, Z., Heng J.Y.Y. et al., Sep. Purif. Technol., 2020, Vol. 253, 117536. DOI: 10.1016/j.seppur.2020.117536.

63. Gadipelli S., Guo Z. X., Prog. Mater. Sci., 2015, Vol. 69, pp. 1-60.DOI: 10.1016/j.pmatsci. 2014.10.004.

64. He H., Klinowski J., Forster M., Lerf A., Chem. Phys. Lett., 1998, Vol. 287, No 1-2, pp. 53-56. DOI:10.1016/s0009-2614(98)00144-4.

65. Gao W., Graphene Oxide, 2018, pp. 6195. DOI:10.1007/978-3-319-15500-5 3.

66. Jinghai L., Wanfei L., Limei D., Xin L. et al., Nano Letters, 2015, Vol. 15, No 8, pp. 5137-5142. DOI: 10.1021/acs.nanolett.5b01919.

67. Liao R., Li M., Li W., Lin X.et al., J. Mater. Sci., 2018, No 53, pp. 5929-5941. DOI: 10.1007/s10853-017-1963-z.

68. Chegeni M., Mousavi Z., Soleymani M., Dehdashtian S., Diam. Relat. Mater., 2020, Vol. 101, pp. 107621. DOI: 10.1016/j.diamond.2019.107621.

69. Banerjee P., Das P., Zaman A., Das P., Process Safety and Environmental Protection, 2016, Vol. 101, pp. 45-53. DOI: 10.1016/ j.psep.2016.01.021.

70. Seung-Woo N., Chanil J., Hang L., Miao Y., et al., Chemosphere, 2015, Vol. 136, pp. 2026. DOI: 10.1016/j.chemosphere.2015.03.061.
71. Bakr A.R., Rahaman M.S., Chemosphere, 2016, Vol. 153, pp. 508-520. DOI: 10.1016 /j.chemosphere.2016.03.078.

72. Álvarez-Torrellas S., Rodríguez A., Ovejero G., García J., Chem. Eng. J., 2016, Vol. 283, pp. 936-947. DOI: 10.1016/j.cej. 2015.08.023.

73. Nyankson E., Kumar R.V., Materials Today Advances, 2019, Vol. 4, 100025. DOI: 10.1016/j.mtadv.2019.100025.

74. El-Sheikh A.H., Qawariq R.F., Abdelghani J.I., Environ. Technol. Innov., 2019, Vol. 16, pp. 100496. DOI: 10.1016/j.eti.2019. 100496

75. Hu X., Cheng Z., Chin. J. Chem. Eng., 2015,Vol. 23, No 9, pp. 1551-1556. DOI: 10.1016/j.cjche.2015.06.010.

76. Czech B., Oleszczuk P., Chemosphere, 2016, Vol. 149, pp. 272-278. DOI: 10.1016/ j.chemosphere.2015.12.057.

77. Zhang S., Dong Y., Yang Z., Yang W. et al., Chem. Eng. J., 2016, Vol. 304, pp. 325-334. DOI: 10.1016/j.cej.2016.06.087.

78. Phasuphan W., Praphairaksit N., Imyim A., J. Mol. Liq., 2019, Vol. 294, 111554. DOI: 10.1016/j.molliq.2019.111554.

79. Zhou L., Chen H., Jiang X., Lu F. et al., J. Colloid Interface Sci., 2009, Vol. 332, No 1, pp. 16-21. DOI: 10.1016/j.jcis.2008.12.051.

80.Zeng H., Gao M., Shen T., Ding F., J. Taiwan Inst. Chem. Eng., 2018, Vol. 93, pp. 329-335. DOI: 10.1016/j.jtice.2018.07.038.

81. Talele P., Choudhary S., Kishore N., $J$. Chem. Thermodyn., 2016,Vol. 92, pp. 182190. DOI: 10.1016/j.jct.2015.09.015.

82.Charnay C., Bégu S., Tourné-Péteilh C., Nicole L. et al., Eur. J. Pharm. Biopharm., 2004, Vol. 57, No 3, pp. 533-540. DOI: 10.1016/j.ejpb.2003.12.007.

83.Lang Y., Finn D. P., Pandit A., Walsh P.J., J. Mater. Sci. Mater. Med., 2011, Vol. 23, No 1, 73-80. DOI: 10.1007/s10856-011-4488-z.

84.Krajišnik D., Daković A., Milojević M., Malenović A. et al., Colloids Surf. B, 2011, Vol. 83, No 1, pp. 165-172. DOI: 10.1016/ j.colsurfb.2010.11.024.

85. Goscianska J., Olejnik A., Nowak I., Marciniak M. et al., Eur. J. Pharm. Biopharm.,2015, Vol. 94, pp. 550-558. DOI: 10.1016/j.ejpb.2015.07.003.

86. Goscianska J., Olejnik A., Pietrzak R., Mater. Chem. Phys., 2013, Vol. 142, No 2-3, 586-593. DOI: 10.1016/j.matchemphys.2013.07.057.

87. Almeida H.F.D., Neves M.C., Trindade T., Marrucho I.M. et al., Chem. Eng. J., 2019, 
Vol. 381, 122616. DOI: 10.1016/j.cej.2019. 122616.

88.Zadaka D., Mishael Y., Polubesova T., Serban C. et al., Appl. Clay. Sci., 2007, Vol. 36, No 1-3, pp. 174-181. DOI: 10.1016/j.clay. 2006.04.012.

89. Thiebault T., Boussafir M., Fougère L., Destandau E. et al., Environ. Nanotechnol. Monit. Manag., 2019, Vol. 12, 100266. DOI: 10.1016/j.enmm.2019.100266.

90.Khazri H., Ghorbel-Abid I., Kalfat R., Trabelsi-Ayadi M., Appl. Water. Sci., 2017, Vol. 7, pp.3031-3040. DOI: 10.1007/s13201-016-0414-3.

91.Al-rimawi F., Daana M., Khamis M., Karaman R. et al., Arab. J. Sci. Eng., 2019, Vol. 44, pp.209-215. DOI: 10.1007/s13369-018-3406-9.

92.Sukhanov P.T., Savvina A.G., Kushnir A.A., Poluzhenkova E.V., Analitika I kontrol', 2018, Vol. 22, No 2, pp. 92-116.DOI: 10.15826/analitika.2018.22.2.003.

93.Martín J., del Mar Orta M., MedinaCarrasco S., Luis Santos J. et al., Appl. Clay. Sci., 2019, Vol. 171, pp. 29-37. DOI: 10.1016/j.clay.2019.02.002.

94.Ghemit R., Makhloufi A., Djebri N., Flilissa A. et al., Groundw. Sustain. Dev., 2019, Vol. 8, pp. 520-529. DOI: 10.1016/j.gsd.2019.02.004.

95. Tiwari D., Chem. Eng. J., 2015, Vol. 263, pp. 364-373. DOI: 10.1016/j.cej.2014.10.102.

96. Li Z., Gómez-Avilés A., Sellaoui L., Bedia J. et al., Chem. Eng. J., 2019, Vol. 371, pp. 868-875. DOI: 10.1016/j.cej.2019.04.138.

97. Wang Z., Liao L., Hursthouse A., Song N. et al., China. Int. J. Environ. Res. Public Health, 2018, Vol. 15, No 8, 1653. DOI:10.3390/ijerph15081653.

98. Rafati L., Ehrampoush M.H., Rafati A.A., Mokhtari M. et al., International Journal of Environmental Science and Technology, 2017, Vol. 15, pp. 513-524. DOI: 10.1007/s13762-017-1393-0.

99. Mojiri A., AndashtKazeroon R., Gholami A., Water, 2019, Vol. 11, No 3, 551. DOI:10.3390/w11030551.

100.Garcia M.J.J., P. Nuñez J.A., Salapare H.S., Vasquez Jr.M.R., Results in Physics, 2019,Vol. 15, pp. 102629. DOI: 10.1016/ j.rinp.2019.102629.

101. Maia G.S., de Andrade J.R., da Silva M.G.C., Vieira M.G.A., Powder Technology, 2019, Vol. 345, pp. 140-150. DOI: 10.1016/j.powtec.2018.12.097.

102. Ahmed F.R., Shoaib M.H., Yosuf R.I., Ali T. et al., Eur J Pharm Sci., 2019, Vol. 133,pp. 214-227. DOI: 10.1016/j.jps.2019.03.028.
103.Kierys A., Kasperek R., Krasucka P., Goworek J., Colloids Surf. B, 2016, Vol. 142, pp. 30-37. DOI: 10.1016/j.colsurfb.2016.02.041.

104.Perisic D.J., Gilja V., Stankov M.N., Katancic Z. et al., J. Photochem. Photobiol. A, 2016, Vol. 321, pp. 238-247. DOI: 10.1016/ j.jphotochem.2016.01.030.

105. Mironenko N.V., Brezhneva T.A., Selemenev V.F., Russ. J. Phys. Chem. B, 2013, Vol. 87, No 3, pp. 368-371. DOI: 10.1134/ s0036024413030175.

106. Sinyaeva L.A., Belanova N.A., Karpov S.I., Selemenev V.F. et al., J. Anal Chem, 2018, Vol. 73, No 9, pp. 847-854. DOI: 10.1134/ s1061934818090149.

107. Cao Nhat L., Zyablov A.N., Duvanova O.V., Selemenev V.F., Izv. Vyssh. Uchebn. Zaved. Khim. Khim. Tekhnol., 2020, Vol. 63, No 2, pp. 71-76. DOI: 10.6060/ivkkt. 20206302.6071.

108. Kushnir A.A., Sukhanov P.T., Savvina A.G., Bondareva L.P. et al., Russ. J. Appl. Chem., 2016, Vol. 89, No 6, pp. 891-896. DOI: 10.1134/s1070427216060070.

109. Gubin A.S., Sukhanov P.T., Kushnir A.A., Moscow Univ. Chem. Bull., 2019, Vol. 74, No 5, pp. 257-264. DOI: 10.3103/ s0027131419050055.

110. Gubin A.S., Sukhanov P.T., Kushnir A.A., Proskuryakova E.D., Russ. J. Appl. Chem., 2018, Vol. 91, No 10, pp. 1626-1634. DOI:10.1134/s1070427218100099.

111. Mphahlele K., Onyango M.S., Mhlanga S.D., J. Environ. Chem. Eng., 2015, Vol. 3, No 4, pp. 2619-2630. DOI: 10.1016/ j.jece.2015.02.018.

112.Cantarella M., Carroccio S. C., Dattilo S., Avolio R. et al., Chem. Eng. J., 2019, Vol. 367, pp. 180-188. DOI: 10.1016/j.cej.2019.02.146.

113.Canfarotta F., Poma A., Guerreiro A., Piletsky S., Nature Protocols, 2016, Vol. 11, No 3, pp. 443-455. DOI:10.1038/nprot.2016.030.

114.Eslami M.R., Alizadeh N., Sens. Actuators B Chem., 2015, Vol. 220, pp. 880887. DOI: $10.1016 /$ j.snb.2015.06.017

115. Madikizela L.M., Chimuka L., J. Environ. Chem. Eng., 2016, Vol. 4, No 4, pp. 40294037. DOI: $10.1016 /$ j.jece.2016.09.012.

116.Guo P., Yuan X., Zhang J., Wang B. et al., Anal. Bioanal. Chem., 2018, Vol. 410, No 2, pp. 373-389. DOI: 10.1007/s00216-0170727-6.

117. Cássio Santos da Silva R., Nishikawa Santos M., Pires B.C., Fonseca Dinali L.A. et al., J. Environ. Chem. Eng., 2019, Vol. 7, No 2, 
2019, pp. 103037. DOI: 10.1016/j.jece. 2019.103037.

118. Kierys A., Grochowicz M., Kosik P., Microporous Mesoporous Mater., 2015, Vol. 217, pp. 133-140. DOI: 10.1016/j.micromeso. 2015.06.009.

119.Tiwari D., Lalhriatpuia C., Lee S.-M., J. Ind. Eng. Chem., 2015, Vol. 30, pp. 167-173. DOI: 10.1016/j.jiec.2015.05.018.

120. Tan P., Jiang Y., Liu X., Sun L., J. Chem. Eng., 2019, Vol. 27, No 6, pp. 13241338. DOI: 10.1016/j.cjche.2018.11.004.

121.Wang J., Li H., Shuang C., Li A., Wang C. et al., Microporous Mesoporous Mater., 2015, Vol. 210, pp. 94-100. DOI: 10.1016/ j.micromeso.2015.02.026

122.Beiraghi A., Pourghazi K., Amoli-Diva M., Chem. Eng. Sci., 2014, Vol. 108, pp. 103110. DOI: 10.1016/j.ces.2013.12.044.

123.Jiang M., Yang W., Zhang Z., Yang Z. et al., J. Environ, Sci, 2015, Vol. 31, pp. 226234. DOI: $10.1016 /$ j.jes.2014.09.035

124.Sun W., Li H., Li H., Li S. et al., Chem. Eng. J., 2019, Vol. 360, pp. 645-653. DOI: 10.1016/j.cej.2018.12.021

125. Hasan Z., Khan N.A., Jhung S.H., Chem. Eng. J., 2016, Vol. 284, pp. 1406-1413. DOI:10.1016/j.cej.2015.08.087.

Кушнир Алексей Алексеевич - к.х.н., доцент кафедры технологии органических соединений, переработки полимеров и техносферной безопасности, Воронежский государственный университет инженерных технологий, Воронеж

Сыпко Ксения Сергеевна - старший преподаватель кафедры химической технологии, машин и аппаратов химических производств, Невинномысский технологический институт (филиал) ФГАОУ ВО «СевероКавказский федеральный университет», Невинномысск

Губин Александр Сергеевич - к.х.н., доцент кафедры технологии органических соединений, переработки полимеров и техносферной безопасности, Воронежский государственный университет инженерных технологий, Воронеж

Шеремет Екатерина Олеговна - студентка факультета экологии и химической технологии, Воронежский государственный университет инженерных технологий, Воронеж

Суханов Павел Тихонович - Д.х.н., профессор кафедры физической и аналитической химии, Воронежский государственный университет инженерных технологий, Воронеж
126. Zhuang S., Rong C., Wang J., Chem. Eng. J., 2019, Vol. 359, pp. 354-362. DOI: 10.1016/j.cej.2018.11.150.

127. Bhadra B.N., Ahmed I., Kim S., Jhung S. H., Chem. Eng. J., 2016, Vol. 314, pp. 50-58. DOI: 10.1016/j.cej.2016.12.127.

128. Luo Z., Fan S., Liu J., Liu W. et al. Water. Polymers, 2018, Vol. 10, No 2, pp. 209. DOI: $10.3390 /$ polym10020209.

129. Liu W., Shen X., Han Y., Liu Z. et al., Chemosphere, 2019, Vol. 215, pp. 524-531, DOI: 10.1016/j.chemosphere.2018.10.075.

130.Singco B., Liu L.-H., Chen Y.-T., Shih Y.-H. et al., Microporous Mesoporous Mater., 2016, Vol. 223, pp. 254-260. DOI: 10.1016/j.micromeso.2015.08.017.

131.Kollarahithlu S.C., Balakrishnan R.M., Environ. $\quad$ Sci. $\quad$ Pollut. Res., 2019, Vol. 26, pp. 34117-34126. DOI: 10.1007 /s11356-018-3272-8.

132.Sarp G., Yilmaz E., MicrochimicaActa, 2019, Vol. 186, No 11, pp. 744. DOI: 10.1007/s00604-019-3875-x.

Kushnir Aleksei A. - Ph.D., Associate Professor, Department of Compound Technology, Polymer Converters and Technosphere Safety, Voronezh state university of engineering technologies, Voronezh. e-mail: kushnir_aleksei@mail.ru

Sypko Ksenia S. - Senior Lecturer of the Department of Chemical Technologies, Machines and Apparatus for Chemical Production, Nevinnomyssk Technological Institute (branch) of the Federal State Autonomous Educational Institution of Higher Education "North Caucasus Federal University", Nevinnomyssk. e-mail: kssypko@mail.ru

Gubin Aleksander S. - Ph.D., Associate Professor, Department of Compound Technology, Polymer Converters and Technosphere Safety, Voronezh state university of engineering technologies, Voronezh. e-mail: goubinne@mail.ru.

Sheremet Ekaterina O. - student of the Faculty of Ecology and Chemical Technology, Voronezh state university of engineering technologies, Voronezh. e-mail: c.scheremet@yandex.ru.

Sukhanov Pavel T. - professor, doctor of science (chemistry), Department of Physical and Analytical Chemistry, Voronezh state university of engineering technologies, Voronezh. e-mail: pavel.suhanov@mail.ru 